possessed of a genuine passion to see life as a whole and no less genuine faith that in the study of the "works of creation" they were enlarging man's knowledge of the wisdom of God. They pursued a synthetic philosophy, and the progress they made in the halfcentury of their greatness was large in extent and true in direction. Though they accepted data which we with nearly three centuries of further study rightly reject, it was their catholicity of outlook, and their willingness to prove all things, that made possible the speed and range of their achievements. If they had been less hospitable to old or new, if they had refused fresh notions through subservience to the past or renounced authority recklessly and in revolt, they would neither have laid the foundations for scientific inquiry nor effected so large and permanent a revolution. Canon Raven believes that it is arguable that there has never been so fine an attempt to formulate a synthetic philosophy as that which the Cambridge Platonists projected and Culverwel succeeded in expressing. Like the best of the medievals, they saw the world as emblematic or sacramental : like the best of the moderns, they stroy to see it objectively and accurately.

\section{Hospital Staffs and Working Conditions}

THE urgency of the recent appeal for more nurses, midwives and a mestic hospital workers is clearly set forth if Me Government booklet "Staffing the Hospit s, aargent National Need" (H.M. Stationery Office, 45. 3d. net). This booklet gives details of the unafimous agreement reached between the Gowfiment and the various hospital organisations. The Minister of Health, the Secretary for Scotland and the Minister of Labour and National Service say that "the situation is serious already. It is likely soon to become critical unless thousands of new recruits can be obtained quickly." The Government and the hospital authorities have agreed upon salary increases, improved working conditions and prospects, the formation of a national reserve of nurses, much-needed reforms such as the employment of married and part-time nurses and permission to live out of hospital, the training of more male nurses and the formation of a grade of 'ward orderlies' to assist the nurses. A National Joint Council for England and Wales has been formed to regulate the terms and conditions of service of hospital domestic workers. Further details of the proposed reforms are given in a memorandum issued with the booklet just mentioned. Certainly reform of the lot of the hospital worker has been, as every medical man will testify, overdue for many years. Without it we can scarcely bope to obtain enough workers to operate any national health scheme.

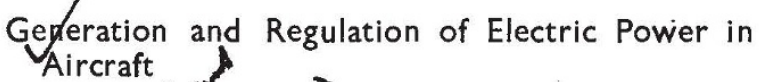

A PAPER I. O. Hodkmeyer (J. Inst. Elec. Eng., 93, Pt. No. 31, February 1946) records the developm tht of theneration of D.C. power in aircraf by wind fill- and engine-driven generators, from its inception to the present day. Features of generatory design which have called for special considepation, or have been the subject of failure, are discussed. Sections are devoted to the choice of speod range, brush wear at high altitude, systems of veptilation, design of end-frames, and bearing failure. Some mention is made of generators designed for power supply to radio equipment, as distinct from general power services. These generators, which include high-voltage D.c. machines and high-frequency A.c. machines, have been combined with low-voltage D.c. machines, both in tandem and with a common magnet system.

The latter part of the paper deals with voltage regulation in so far as generator design is influenced by the system adopted; self-regulating generators of various types have been used from time to time in the past. Brief mention is made of the design of the several types of regulator which have been used, including Tirrill and carbon-pile types. The paper shows how the control of the system voltage had been conditioned by the inclusion of an accumulator, and how it has not been possible to devise a system which gives the constant line voltage required for currentusing devices, and, at the same time, permit of adequate control of accumulator-charging current. Systems of paralleling, and their effect on line voltage, are also described.

\section{Small Two-phase Jnduction Motor}

A specrastismall motor, developed in the Admiralty Coupass Dephrtment for use in applying torques folfontrolling phe precession of the gyros of the Admirelty Gyo Trahsmission Unit Mk. II, has now ben descrilgd. The motor is totally enclosed and has ancuminium alloy shell and end shield. The rotor ifindunted in ball bearings and the weight of the fop fiplete motor is $5 \frac{1}{2} \mathrm{oz}$. It is suitable for use in tpelcal countries. The stator core consists of radiometal laminations 0.010 in. thick. The stator windings are of the double-layer concentrated type, the Individual coils being preformed and inserted in the 12-slot core to form a 2-phase 6-pole system. The squirrel-cage rotor is formed by copper strips secured in narrow slots in the laminations; the twenty-one slots are skewed by one slot pitch to eliminate cogging. The shaft is of stainless steel. The deep narrow rotor bars and open-ended slots assist in providing a relatively flat speed-torque characteristic, since at high slip frequencies the current in the bars is concentrated towards the outer edge giving effectively greater rotor resistance at low rotor speeds. As a torque motor, the machine was required to operate on $333 \mathrm{c.} / \mathrm{s}$. and works continuously under standstill conditions, with a temperature rise at 20 volts/phase of about $30^{\circ} \mathrm{C}$. As a follow-up motor, at a frequency of $400 \mathrm{c} . / \mathrm{s}$. , one phase is constantly energized, while the second phase is supplied from the output of a valve amplifier in proportion to the misalignment of following. Under these conditions a fixed phase voltage of 30 volts gives a temperature rise of about $30^{\circ} \mathrm{C}$. in normal operation.

\section{General Purposf Source-unit for Spectrographic Analysis \\ Foun man types of light source are used for the} spectroge phic analysis of metals and alloys. They are the low-voltage D.c. are, the high-voltage A.c. atce the condensed spark either controlled or uncontrolod, and the low-voltage discharge initiated by a low-energy, high-voltage spark. Since they require only simple and inexpensive equipment, the D.C. are and the uncontrolled condensed spark are generally used in Britain, the are for work of high sensitivity but not high accuracy because of its instability, the spark for accurate analysis. For the accuracy and wide field of application required by present-day 